American Journal of Pharmaceutical Education 2020; 84 (2) Article 7556.

\title{
BRIEF
}

\section{Implementation of the Pharmacists' Patient Care Process in a Medicinal Chemistry Course}

\author{
Naser Z. Alsharif, PharmD, PhD, Michele A. Faulkner, PharmD \\ School of Pharmacy and Health Professions, Creighton University, Omaha, Nebraska \\ Submitted February 10, 2019; accepted August 8, 2019; published February 2020.
}

Objective. To implement the Pharmacists' Patient Care Process (PPCP) in a medicinal chemistry course.

Methods. Doctor of Pharmacy students in a medicinal chemistry course were challenged to apply the PPCP in a lesson on cholinesterase inhibitors and NMDA receptor antagonist in the treatment of Alzheimer's disease. A clinical faculty member with expertise in the topic reviewed the clinical information provided to ensure applicability to patient care. A pre- and post-course survey was administered to assess students' understanding of the PPCP and the effectiveness of the strategies used. Students' pre- and post-course responses were analyzed, and qualitative themes were identified.

Results. Of the 141 students enrolled in the course, $96 \%$ and $97 \%$ completed the pre- and post-course surveys, respectively. Students' post-course responses were higher than pre-course answers to the question that they knew all the steps of the PPCP (96\% vs 66\%, respectively). Ninety one percent in the post-course survey compared to $62 \%$ in the pre-course survey listed the PPCP steps correctly. In addition, more than $90 \%$ of the students indicated that the strategies used in the class helped them understand and relate to the PPCP. Qualitative responses revealed themes with positive responses related to the course, course activities, PPCP goals and curriculum design based on the implementation of the PPCP.

Conclusion. The introduction of the PPCP as a framework for all pharmacy practitioners is a worthy endeavor. Purposeful strategies to introduce the PPCP in a medicinal course were positively received by students. Formalized efforts to implement the PPCP in clinical, social and administrative, and science courses are critical to introduce the PPCP as a framework for all future pharmacy practitioners. Keywords: medicinal chemistry, Pharmacists' Patient Care Process, clinical relevance, drug structure, pharmacophore, Alzheimer's disease

\section{INTRODUCTION}

Over the last several decades, pharmacy has evolved from an apprenticeship model to a patient-centered model. Pharmaceutical care and medication therapy management were introduced and developed to help pharmacists as they address their patients' health care needs. ${ }^{1,2}$ However, many stakeholders, including the public, are still not clear about the role pharmacists can play as part of the healthcare team. Additionally, third-party payers have not been forthcoming in reimbursement of pharmacists for cognitive services such as health promotion (eg, smoking cessation), medication therapy management, and preventive care services

Corresponding Author: Naser Z. Alsharif, School of Pharmacy and Health Professions, Creighton University Medical Center, 2500 California Plaza, Omaha, NE 68178. Tel: 402-280-1857. Fax: 402-280-1883. Email: nalshari@, creighton.edu. (eg, diabetes prevention). ${ }^{3-5}$ To address the above challenges, the pharmacy organizations section of the Joint Commission of Pharmacy Practitioners (JCPP), in collaboration with the Academy, began introducing the Pharmacists' Patient Care Process (PPCP) in $2014 .^{6}$ The goal of the PPCP was to establish a thought process and framework for how pharmacists should consistently approach patient care in all practice settings. ${ }^{6}$ This consistent approach will help key stakeholders become more aware of the role pharmacists play as members of the healthcare team. Several pharmacy organizations, including the American College of Clinical Pharmacy (ACCP) and the Accreditation Council for Pharmacy Education (ACPE), have supported the incorporation of this consistent approach in the training of current and future pharmacists. ${ }^{7,8}$ Pharmacy schools have been asked to implement the PPCP into their curriculum, including into the clinical, science, and social and administrative courses. The American 


\section{American Journal of Pharmaceutical Education 2020; 84 (2) Article 7556.}

Association of Colleges of Pharmacy (AACP) has taken the lead on this, and in 2016, charged a catalyst team and an implementation team with representatives from several universities to help initiate the process in partnership with approximately 30 schools and colleges of pharmacy. 9

During the last 25 years, we have implemented several strategies to introduce clinical relevance into our Chemical Basis of Drug Action course (commonly known as the "medicinal chemistry course"). ${ }^{10-13}$ The structurally based therapeutic evaluation (SBTE) concept was introduced in our course in 1996 to include seven therapeutic criteria in the analysis of drug structure to aid in making therapeutic decisions based on patient scenarios. ${ }^{10}$ The SBTE has also been used to help students meet educational outcomes related to therapeutic decision making and integration of concepts from other courses. ${ }^{11} \mathrm{We}$ followed this with an instructional model that combines the SBTE concept and cognitive (Bloom's Taxonomy) and affective (Krathwol's Taxonomy) pedagogy over six sections for each lesson including: Introduction, Pharmacophore, Structure Activity Relationship, Application of SAR to Marketed Products, Summary of Common Clinical Decisions, and Predicting Clinical Activity. The end goal of these strategies is to help students achieve the higher level of thinking required to make therapeutic decisions based on drug structure, and to acquire the appropriate attitude to appreciate the knowledge delivered in the Chemical Basis of Drug Action course. ${ }^{13,14}$ A computer software program, SoftChalk Cloud (SoftChalk, Richmond, $\mathrm{VA})^{15}$ is used to author online lessons. This allows for student interactivity with the content by embedding questions and exercises to emphasize concepts discussed in each of the six lesson sections. ${ }^{16}$ Although not intentionally designed to do so, the above strategies encompass key aspects of the five steps of the PPCP (ie, collect, assess, plan, implement, and follow-up). In this manuscript, we describe purposeful approaches within our prior strategies to incorporate the PPCP into the Chemical Basis of Drug Action course.

\section{METHODS}

The pharmacy program at the School of Pharmacy and Health Professions at Creighton University is a typical twoyear pre-pharmacy curriculum followed by a four-year professional program. The Chemical Basis of Drug Action course is taught in the fall semester for second year (P2) campus and distance students. ${ }^{17}$ In academic year 2017 2018, 75 campus and 66 distance students took the course at the same time and used the same course website. The course was 2.5 credit hours and the lessons were divided among three faculty members (approximately 11 lectures each). The course did not require a textbook. Students accessed course content via interactive Word documents and, for the lesson described in this study, the SoftChalk Cloud software. ${ }^{17}$
Student familiarity with the PPCP was assessed via a survey administered at the beginning of the semester. The PPCP was then introduced during course orientation, both in a SoftChalk lesson and in the 11 interactive in-class lectures pertaining to the five drug classes that incorporated the PPCP. In this paper, only the lesson on cholinesterase inhibitors (CIs) and the N-methyl-D-aspartate (NMDA) receptor antagonist (Figure 1) and their use in the treatment of Alzheimer's disease is presented. A clinical faculty member with expertise in Alzheimer's disease reviewed all the clinical information provided for the students to ensure its clinical relevance and applicability to patient care.

A summary of some of the key information presented in sections I-VI of the SoftChalk lesson and reemphasized in the in-class interactive session are provided in Appendix I. ${ }^{18-30}$ A patient case (see Appendix 2) was introduced in section I and was revisited in each of the remaining five lesson sections. Students were challenged to reflect on the case as medicinal chemistry information was introduced in sections II -IV of each lesson, with emphasis placed on the first three steps of the PPCP: collect, assess and plan. Questions were embedded in each section of the SoftChalk lesson as well as in pop ups, hyperlinks, and videos to facilitate this process and help the students see the "big picture" related to the CIs and NMDA receptor antagonist in the treatment of Alzheimer's disease. (For more information and details on all the SoftChalk cholinesterase inhibitors lesson sections, the reader can access the complete SoftChalk lesson link https://www.softchalkcloud.com/lesson/fRoEcJtPQgN50B). Students were accountable for learning information that would allow them to make clinical decisions based on the drug structure. Students were surveyed again following completion of the course to assess their understanding of the PPCP and the effectiveness of the strategies used in the five lessons in helping them apply the PPCP. The preand post-course surveys were authored in the course platform, Blueline, and were only accessible using the students' personal username and password. The institutional review board (IRB) at Creighton University deemed this project exempt. Student pre- and postcourse quantitative responses were analyzed using descriptive statistics. The two authors examined the qualitative responses separately, highlighted sections of each student responses, identified patterns among the highlighted sections and came up with themes. Then they met to compare notes and agree upon the final themes.

\section{RESULTS}

The response rates for the pre- and post-course surveys were $96 \%(n=130)$ and $97 \%(n=131)$, respectively. 


\section{American Journal of Pharmaceutical Education 2020; 84 (2) Article 7556.}

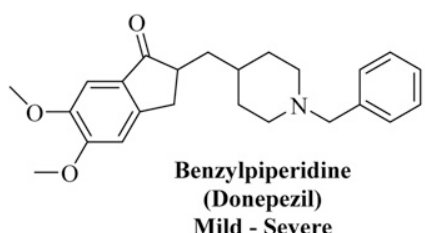

Mild - Severe
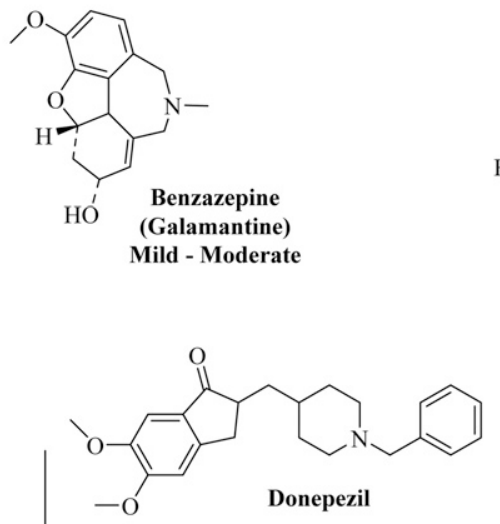

Benzylpiperidine + 3,5-dimethyl-adamantan-1-amine (Namzaric $\left.{ }^{\circledR}\right)$

Moderate-Severe

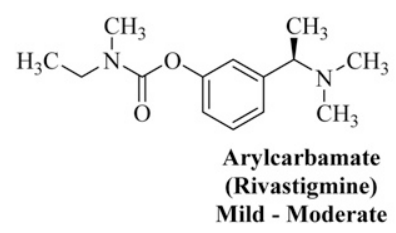

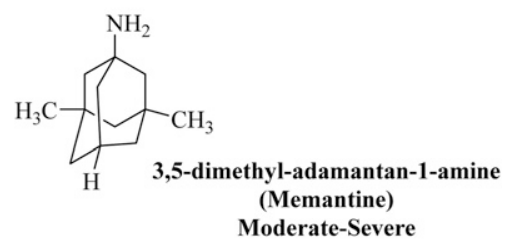

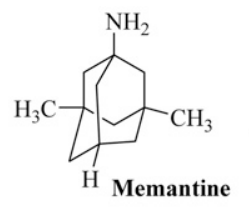

ne

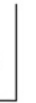

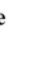

Figure 1. Cholinesterase Inhibitors and N-methyl-D-transferase Receptor Antagonist Pharmacophore, Generic Name and Their Indication for Treatment of Alzheimer's Disease

At the start of the course, a majority of the students $(>97 \%)$ knew what the PPCP means and the rationale for implementing it. Sixty-six percent of the students indicated that they knew all the steps of the PPCP, with $62 \%$ listing those steps correctly in the pre-course survey (Table 1). In the post-course survey, this knowledge of the steps of the PPCP increased to $96 \%$ and $91 \%$, respectively. While $28 \%$ incorrectly answered "true" in the precourse survey to the statement that the PPCP is applicable only to the hospital pharmacy setting, only $3 \%$ answered true in the post-course survey. In addition, all students answered agree or strongly agree to the statement that the PPCP is an essential aspect of current and future pharmacy practice (Table 1 ).

A vast majority $(90 \%)$ of the students indicated the lessons that incorporated the PPCP helped them to understand the importance of the process in patient care (Table 2). This was also true for the case study, which was introduced in the SoftChalk lessons, with $91 \%$ of the students indicating that the cases helped them to relate more to the PPCP. Following each lesson, a table exercise was provided in a document on the course website and the students were challenged to complete the content and PPCP application columns based on clinical scenarios for the specific drug class discussed. Table 3 is an example of what is expected from the students based on the Alzheimer's disease lesson. Eighty-five percent of the students indicated that the table helped them relate to how the PPCP can be consistently applied in their patients' care. In addition, $90 \%$ and $92 \%$ of the students shared that the emphasis on the PPCP in the Chemical Basis of Drug Action course helped them to relate more to the key steps of the PPCP and that the introduction of the PPCP in the course helped them to establish a thought process and framework for how to consistently approach patient care. Finally, to gauge the extent to which the PPCP was being introduced in other courses, $79 \%$ of the students did indicate that two of the other courses concurrently offered (Pharmacotherapeutics I and Patient Assessment) introduced and/or emphasized the PPCP to the same level as in Chemical Basis of Drug Action course.

Students' qualitative responses supported many of their quantitative responses (Tables 1 and 2) and identified several themes related to the Chemical Basis of Drug Action course in general and to specific course activities (Table 4). Themes from students' comments revealed an appreciation of the extensive effort made to implement the PPCP into the course because it supported their learning and helped them understand how medicinal chemistry relates to clinical practice. With regards to the course activities, students valued the use of the SoftChalk Cloud software as a medium for presentation of the PPCP and shared that it helped them apply the PPCP to lessons 


\section{American Journal of Pharmaceutical Education 2020; 84 (2) Article 7556.}

Table 1. Results of a Survey Administered to Doctor of Pharmacy Students Before and After Completing a Medicinal Chemistry Course in Which the Pharmacist-Patient Care Process was Implemented

\begin{tabular}{lcc}
\hline Survey Item & Pre-course Response (n=135) \% (n) & Post-Course Response (n=135) \% (n) \\
\hline The PPCP Stands for & $98(132)$ & $99(134)$ \\
I know all the steps of the PPCP & $66(89)$ & $96(130)$ \\
List the steps of the PPCP in the right order & $62(84)$ & $91(123)$ \\
The PPCP is meant to establish an identity for & True: $99(134)$ & True: $99(134)$ \\
pharmacists by establishing a thought process & False: $1(1)$ & False: $1(1)$ \\
and framework for how pharmacists should & & \\
consistently approach their patient care, that & & \\
is unique to what they do to enhance patient & & \\
care. & True: $28(38)$ & \\
The PPCP is applicable to only hospital & False: $72(97)$ & True: $3(4)$ \\
pharmacy settings & SA: $82(11)$ & False: $97(131)$ \\
From my current understanding of the PPCP, it & A: $17(23)$ & SA: $88(119)$ \\
is an essential aspect for current and future & N: 0 & A: $12(16)$ \\
pharmacy practice & D: 0 & N: 0 \\
& SD: $1(1)$ & D: 0 \\
& SD: 0 \\
\hline
\end{tabular}

Abbreviations: $\mathrm{PPCP}=$ Pharmacist-Patient Care Process, $\mathrm{SA}=$ Strongly Agree, $\mathrm{A}=$ Agree, $\mathrm{N}=$ Neutral, $\mathrm{D}=$ Disagree, $\mathrm{SD}=$ Strongly Disagree

from faculty members who did not use SoftChalk Cloud. Students also indicated that they appreciated the incorporation of a patient case as part of the lesson as well as the inclass active-learning activities related to the PPCP.

One of the major goals of the PPCP is to develop a consistent framework for practice. Students commented on how the introduction of the PPCP in the course helped them see the overall applicability of the PPCP and how the introduction of the PPCP at this early stage is important in understanding the process. Students shared that the introduction of the PPCP in the Chemical Basis of Drug Action course helped them in other courses in the curriculum, that it was good to learn it from different approaches, and that other courses could learn from how this course introduced the PPCP.

Although the vast majority of the responses were positive, students did provide negative responses. Three students commented that the PPCP was introduced in the pharmacotherapeutics course and therefore it was not necessary to introduce it in the Chemical Basis of Drug Action course. Seventeen students pointed out the need for consistency and incorporation of the process by all three instructors in the course. Some students suggested incorporating other cases in the SoftChalk lesson as well as questions to challenge the students to implement the process more often.

\section{DISCUSSION}

Introducing the PPCP in the education and training of pharmacy students is a worthy effort. ${ }^{6-9}$ In education, this will require developing a new culture across the curriculum in both the didactic and experiential components. Faculty development is needed to help faculty members incorporate the PPCP as well as sharing of successful efforts to motivate other faculty members to reflect on ways they can help in embedding the PPCP in their courses. The recent vote by AACP House of Delegates passing a PPCP policy statement to ensure the dissemination and use of the PPCP profession-wide, including adopting a common language document, endorsing the role of academic pharmacy as a leader in the dissemination, supporting the instruction of PPCP in all the sciences, and development of preceptors, is a welcomed effort. ${ }^{31}$ However, parallel efforts are needed to inform current pharmacy practitioners, public, other healthcare professionals, third-party payers, governmental agencies, and other key stakeholders in the wider community about the rationale for implementing the PPCP. Concerted efforts are also needed to educate pharmacists in general about the importance of developing this framework for their practice and to be creative and innovative in pursuing alternative reimbursement models for their services. The goal should be to create more job opportunities for pharmacists where their training, knowledge, and overall role in patient care is acknowledged and rewarded.

For current students, it will require teaching students current mechanisms and alternative strategies for reimbursement based on cognitive services and collaborative agreements. ${ }^{3-5,32,33}$ Medicine, for example, has developed several models for their own education and practice over the years as well as models for preceptors to use to 


\section{American Journal of Pharmaceutical Education 2020; 84 (2) Article 7556.}

Table 2. Results of a Survey Administered to Doctor of Pharmacy Students After Completing a Medicinal Chemistry Course in Which the Pharmacist-Patient Care Process Was Implemented

\begin{tabular}{|c|c|c|c|c|c|}
\hline Survey Item & $\mathrm{SA}^{\mathbf{a}}$ & $\mathrm{A}^{\mathrm{a}}$ & $\mathbf{N}^{\mathbf{a}}$ & $\mathrm{D}^{\mathbf{a}}$ & $\mathrm{SD}^{\mathrm{a}}$ \\
\hline $\begin{array}{l}\text { The Cholinesterase inhibitor lesson helped me to understand the } \\
\text { importance of the PPCP in patient care. }\end{array}$ & 66 & 26 & 7 & 1 & 0 \\
\hline $\begin{array}{l}\text { The Anticoagulant lesson helped me to understand the importance of the } \\
\text { PPCP in patient care. }\end{array}$ & 69 & 21 & 9 & 1 & 0 \\
\hline $\begin{array}{l}\text { The diuretics lesson helped me to understand the importance of the PPCP in } \\
\text { patient care. }\end{array}$ & 64 & 27 & 9 & 1 & 0 \\
\hline $\begin{array}{l}\text { The ACEI/ARBs lesson helped me to understand the importance of the } \\
\text { PPCP in patient care. }\end{array}$ & 64 & 28 & 7 & 1 & 0 \\
\hline $\begin{array}{l}\text { The case study introduced in the different sections of the SoftChalk lessons } \\
\text { in each of Dr. Alsharif's lessons (eg, patient with Alzheimer's Disease/ } \\
\text { Cholinesterase Inhibitors Lesson; Patient with DVT following hip } \\
\text { surgery/Anticoagulant Lesson; patient with hypertension and history of } \\
\text { Myocardial Infarction/Beta adrenergic blockers) helped me to relate } \\
\text { more to the PPCP. }\end{array}$ & 67 & 24 & 9 & 0 & 0 \\
\hline $\begin{array}{l}\text { The table exercise in the Cholinesterase Inhibitor lesson PowerPoint, } \\
\text { challenging me to apply the PPCP steps to the treatment of a patient with } \\
\text { Alzheimer's Disease, helped me relate to how the PPCP can be } \\
\text { consistently applied in my patients care. }\end{array}$ & 59 & 26 & 15 & 1 & 0 \\
\hline $\begin{array}{l}\text { The emphasis on the PPCP in Chem Basis PHA337 helped me to relate } \\
\text { more to the key steps in the PPCP. }\end{array}$ & 64 & 26 & 9 & 1 & 0 \\
\hline $\begin{array}{l}\text { The introduction of the PPCP in Chem Basis PHA337 helped me to } \\
\text { establish a thought process and framework for how to consistently } \\
\text { approach my patient care. }\end{array}$ & 66 & 26 & 7 & 1 & 0 \\
\hline $\begin{array}{l}\text { Other courses in the Fall } 2017 \text { introduced/emphasized the PPCP to the } \\
\text { same level as in Chem Basis PHA337. }\end{array}$ & 45 & 34 & 12 & 9 & 1 \\
\hline
\end{tabular}

${ }^{a} \mathrm{SA}=$ Strongly Agree, $\mathrm{A}=$ Agree, $\mathrm{N}=$ Neutral, $\mathrm{D}=$ Disagree, $\mathrm{SD}=$ Strongly Disagree

help shape the next generation of clinicians. ${ }^{34-40}$ For the most part, key stakeholders are aware of what physicians do and they are reimbursed for their services accordingly. Thus, learning from the experience of medicine and other healthcare professionals in establishing a framework for their own education and practice is important to overcome some of the obstacles encountered as pharmacists establish their role as members of the healthcare team.

Few publications are available on the implementation of the PPCP in pharmacy schools and none exist regarding its implementation in a practice setting. In education, papers have been published on the key steps in the implementation of the PPCP at the level of a program, ${ }^{41}$ the early introduction of the PPCP in the first year of a PharmD program, ${ }^{42}$ the use of video-enhanced casebased activities guided by the PPCP in a second-year PharmD course, ${ }^{43}$ and the implementation of the PPCP into a comprehensive disease management course series. ${ }^{44}$ At this early stage, most schools have either not yet established or are in varying stages of establishing a formal process to implement the PPCP. When we initiated this study, our school had not established a formal process. However, our experience certainly emphasizes that in schools that have not developed a formal process yet or are in the process of doing so, each faculty member teaching a course can certainly develop mechanisms to incorporate aspects of the PPCP. This should start by faculty members from all the sciences self-educating themselves about the PPCP and taking the time to be creative and innovative in how to incorporate it in their course.

In our study, both the quantitative and qualitative data provide evidence that when planned appropriately within a science course, students can benefit and the importance of the PPCP can be strengthened in their minds. Our quantitative data demonstrates that overall student perception of the importance of the process and their overall familiarity with the PPCP and its main steps improved by the end of the semester as did their perception that the process is an essential aspect of their current and future practice (Tables 1 and 2). Student evaluations have been very positive about the clinical relevance of our course. In the three years prior to the study, an average of $91 \%(n=406)$ of the students responded agree or strongly agree to the question that the course prepared them to think like a healthcare professional, compared to $95 \%(n=141)$ in the current study. This shows that the introduction of the PPCP may have 


\section{American Journal of Pharmaceutical Education 2020; 84 (2) Article 7556.}

Table 3. Table Exercise to Challenge Doctor of Pharmacy Students to Apply the Pharmacist-Patient Care Process in all Sections of an Alzheimer's Disease Lesson

\begin{tabular}{|c|c|c|}
\hline Lesson Section & Content & PPCP Application \\
\hline Introduction & $\begin{array}{l}\text { The mechanism of action of CIs, } \\
\text { etiology and signs and symptoms } \\
\text { of each stage of AD as well as a } \\
\text { review of the pharmacology of } \\
\text { each drug class. }\end{array}$ & $\begin{array}{l}\text { Collect information about the signs and symptoms the } \\
\text { patient is experiencing to assess the stage of the disease. } \\
\text { Assess the stage of patient (SA) based on his signs and } \\
\text { symptoms. Students are reminded that pharmacists may } \\
\text { recognize difficulty retaining counseling information or } \\
\text { changes in behavior like getting refills late or too early. }\end{array}$ \\
\hline Pharmacophore & $\begin{array}{l}\text { The pharmacophore for each } \\
\text { marketed product is introduced } \\
\text { with emphasis on which } \\
\text { pharmacophore is used for mild, } \\
\text { moderate or severe AD. Also, the } \\
\text { arylcarbamate was stressed due } \\
\text { to potential cross allergy with } \\
\text { other carbamate type structures. }\end{array}$ & $\begin{array}{l}\text { Assess the information collected and its impact on treatment } \\
\text { based on relating the pharmacophore to the severity of the } \\
\text { disease. For example, the benzylpiperidine (Donepezil), } \\
\text { arylcarbamate (Rivastigmine) and the benzazepine } \\
\text { (Galantamine) are effective for mild-moderate disease. } \\
\text { The benzylpiperidine is approved for severe disease. The } \\
\text { NMDA receptor antagonist (Memantine) alone or in } \\
\text { combination with Donepezil (Namzaric) is used for } \\
\text { moderate-severe AD. }\end{array}$ \\
\hline $\begin{array}{l}\text { Structure Activity } \\
\text { Relationships (SAR) }\end{array}$ & $\begin{array}{l}\text { Detailed summary of the all the } \\
\text { pertinent SAR and their impact } \\
\text { on drug action, selectivity for } \\
\text { brain or peripheral AChE and for } \\
\text { BuChE, side effects, drug } \\
\text { metabolism, duration of action, } \\
\text { drug-drug interactions, drug-food } \\
\text { interaction, drug allergy. }\end{array}$ & $\begin{array}{l}\text { Plan drug therapy with the appropriate drug structure based } \\
\text { on identifying the pharmacophore and the impact of SAR } \\
\text { on duration of action, selectivity to brain AChE as } \\
\text { compared to peripheral AChE, patient prior history of an } \\
\text { allergy to carbamate, liver or kidney disease and other } \\
\text { factors keeping in mind patient medical history, current } \\
\text { history, drug allergy, pharmacokinetic parameters and side } \\
\text { effects experienced and propose a potential drug therapy } \\
\text { for example based on impact of the SAR on duration of } \\
\text { action, selectivity to brain AChE as compared to peripheral } \\
\text { AChE, allergy to carbamate, liver or kidney disease. }\end{array}$ \\
\hline $\begin{array}{l}\text { Apply SAR to Marketed } \\
\text { Products }\end{array}$ & $\begin{array}{l}\text { Re-emphasize the SAR concepts as } \\
\text { they pertain to marketed } \\
\text { products. }\end{array}$ & $\begin{array}{l}\text { Based on all the key information collected and assessed } \\
\text { regarding patient medical history, current history, drug } \\
\text { allergy, pharmacokinetic parameters and side effects } \\
\text { experienced, an analysis of the information is conducted, } \\
\text { an evaluation of the structure of marketed products is } \\
\text { conducted and drug therapy is planned by selecting the } \\
\text { structure which address the pertinent therapeutic criteria } \\
\text { from above. }\end{array}$ \\
\hline $\begin{array}{l}\text { Summary of Most Common } \\
\text { Clinical Decisions }\end{array}$ & $\begin{array}{l}\text { A summary of all the pertinent } \\
\text { clinical decisions which can be } \\
\text { explained by the structure. }\end{array}$ & $\begin{array}{l}\text { Collecting and assessing the pertinent clinical information } \\
\text { to plan the drug therapy based on analyzing drug } \\
\text { structure. }\end{array}$ \\
\hline Predict Activity & $\begin{array}{l}\text { Based on introducing different } \\
\text { patient scenarios. }\end{array}$ & $\begin{array}{l}\text { Collecting and assessing the pertinent clinical information } \\
\text { to plan the drug therapy based on analyzing drug } \\
\text { structure. }\end{array}$ \\
\hline
\end{tabular}

slightly improved an already high level of student satisfaction. The quantitative data also demonstrates that the incorporation of the PPCP in the lessons helped in all aspects of the goals of PPCP and more specifically in establishing consistency, thought process, and a framework for how pharmacists approach a patient's care. In addition, our data support the findings by Rivkin, ${ }^{29}$ which showed that course-embedded assessments are effective in building a foundation for learning the PPCP.
Although not every course lends itself to covering all the steps of the PPCP, our experience shows that courses can find ways to implement some aspects of the process. As shown in our course, we were able to emphasize the first three steps, and as a result, students better appreciated the whole process.

Our experience emphasized that for courses with several instructors, for consistency, it is helpful that they all make an effort to introduce the PPCP, explain the 


\section{American Journal of Pharmaceutical Education 2020; 84 (2) Article 7556.}

Table 4. Major Themes from the Qualitative Data on the Implementation of the Pharmacist

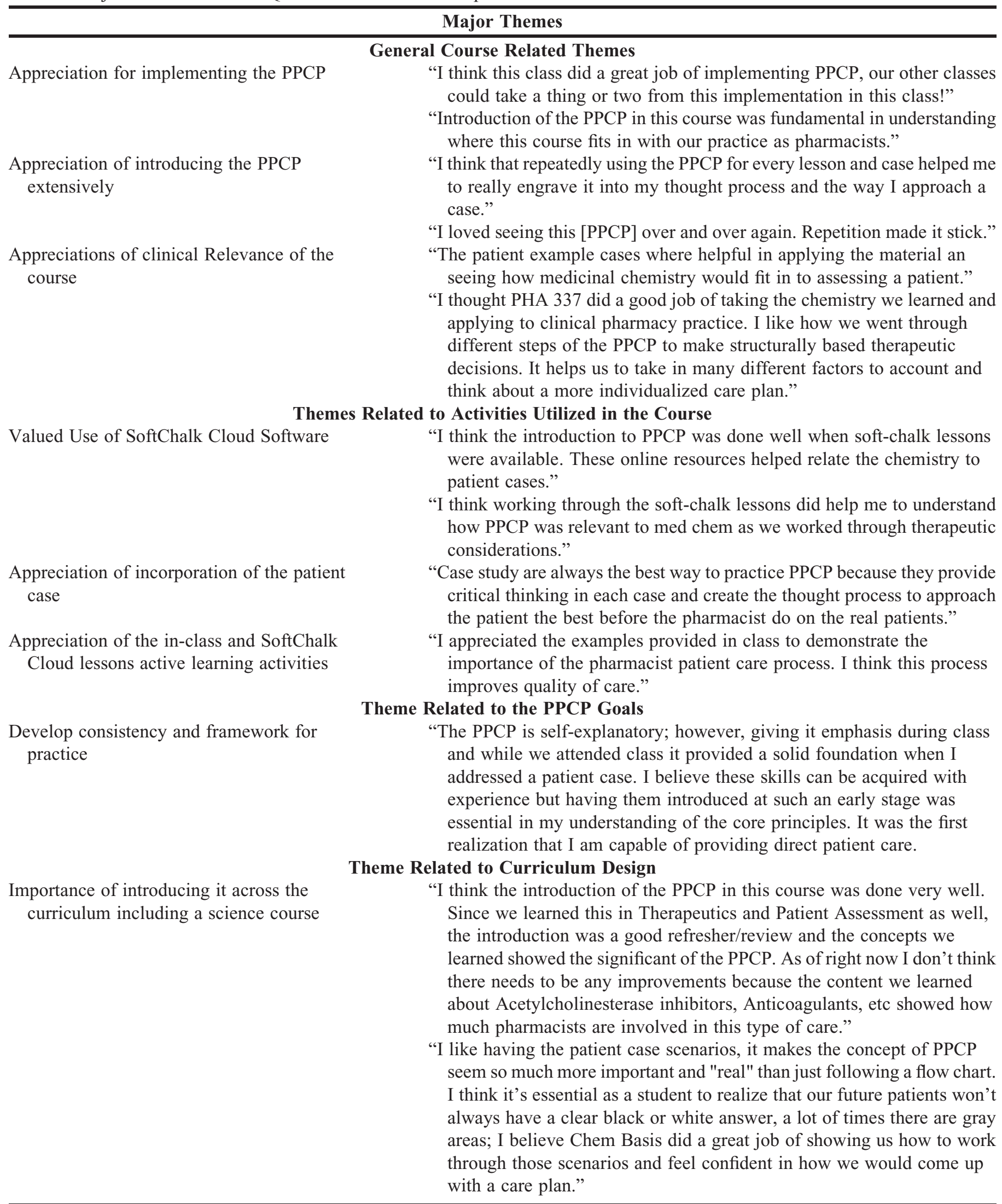




\section{American Journal of Pharmaceutical Education 2020; 84 (2) Article 7556.}

rationale for introducing it, or at a minimum, remind students about the process. Our experience also demonstrated that science courses can play a role in the implementation and reinforcement of the process throughout the curriculum without diluting key aspects of the discipline.

While SoftChalk Cloud was a helpful tool to use in introducing the PPCP, similar efforts can be implemented using a Word document with a case and reinforcing the process throughout the document. Based on this offering, we have introduced a table exercise for students to complete by summarizing all the steps of the PPCP and explaining those steps based on drug structure and the disease state being treated. We have also added different patient cases at the end of the SoftChalk lesson for the students to implement the process. For example, for the antidepressant lesson, we started the lesson with a case of a patient with depression and history of Alzheimer disease. Students had to evaluate the drug structure of the different antidepressant drug classes for the potential for anticholinergic side effects based on the fact the patient has Alzheimer disease. In section VI, we presented several cases, changing the scenario to a patient with agitated depression or depression and a history of benign prostate hypertrophy or a history of seizures or a history of sleep disorder. Based on such information collected, students had to assess drug structure for the potential for causing sedation, anticholinergic side effects, decreasing seizure threshold, or producing a positive or negative effect on sleep pattern, respectively.

At this early stage of implementing the PPCP across schools and colleges of pharmacy, it is important for all faculty members to share their experiences internally and externally. We have presented our experience at our department meetings, shared our experience with the chair of the curriculum committee and with the faculty member assigned at the beginning of 2018 to lead the efforts on implementing the PPCP. We also plan to coordinate our efforts with the faculty teaching patient assessment and module I of therapeutics, two courses identified by students in the fall semester as ones in which the PPCP had been introduced. In addition, we presented our experience in a mini session at the AACP 2018 Annual meeting.

\section{CONCLUSION}

Purposeful strategies to introduce the PPCP in a medicinal course were positively received by students. Formalized efforts to implement the PPCP in clinical, social and administrative, and science courses are critical to introduce the PPCP as a framework for all future pharmacy practitioners.

\section{ACKNOWLEDGMENTS}

The authors recognize Lisa Brennan and Dawn Trojanowski for their valuable review of the final draft of this manuscript.

\section{REFERENCES}

1. Hepler CD, Strand LM. Opportunities and responsibilities in pharmaceutical care Am J Pharm Educ. 1989;53:S7-S15.

2. Robert J. Cipolle, Linda M. Strand, Peter C. Morley.

Pharmaceutical Care Practice: The Patient-Centered Approach to Medication Management Services. McGraw-Hill 2012.

3. Farris KB, Kumbera P, Halterman T. Outcomes-based pharmacist reimbursement: reimbursing pharmacists for cognitive services. (Part 1 of a 2-part series) Managed Care Pharm. 2002;8(5):383-393.

4. Chui MA, Mott DA, Maxwell L. A qualitative assessment of a community pharmacy cognitive pharmaceutical services program, using a work system approach. Res Soc Admin Pharmacy. 2012;8(3):206-2012.

5. Ashe-Scott M, Hitch WJ, Gilmore-Wilson C, Lugo AM. Billing for pharmacists' cognitive services in physicians' offices: Multiple methods of reimbursement. $J$ Am Pharm Assoc. 2012;52:175-180.

6. Joint Commission of Pharmacy Practitioners. Pharmacists' patient care process. Published May 29, 2014. http://www.pharmacist.com/ sites/default/files/files/PatientCareProcess.pdf. Accessed February 27, 2020

7. Harris IM, Phillips B, Boyce E. Clinical pharmacy should adopt a consistent process of direct patient care. Pharmacotherapy. 2014;34(8):e133-e148.

8. Lin AY. Council of Deans Chair Report, July 2018. Accreditation Council of Pharmacy Education. Accreditation standards and key elements for the professional program leading to the Doctor of Pharmacy degree. Standards 2016. https://www.acpe-accredit.org/ pdf/Standards2016FINAL.pdf. Accessed February 27, 2020.

9. Lin AY. Council of Deans Chair Report, July 2018. Am J Pharm Educ. 2019;83(2):7568.

10. Alsharif NZ, Theesen KA, Roche VF. Structurally-based therapeutic evaluation (SBTE): a therapeutic and practical approach to teaching medicinal chemistry. Am J Pharm Educ. 1997;61:55-60. 11. Alsharif NZ, Roche VF, Destache C. Teaching medicinal chemistry to meet outcome objectives for pharmacy graduates. Am J Pharm Educ. 1999; 63:34-40.

12. Alsharif NZ, Shara M, Roche VF. Structurally-based therapeutic evaluation (SBTE): an opportunity for curriculum integration and interdisciplinary teaching. Am J Pharm Educ. 2001;65:314-323. 13. Alsharif NZ, Galt KA, Mehanna A, Chapman R, Ogunbadeniyi AM. Instructional Model to Teach Clinically Relevant Medicinal Chemistry. Am J Pharm Educ. 2006;70:Article 91.

14. Alsharif NZ, Galt KA. Evaluation of an Instructional Model to Teach Clinically Relevant Medicinal Chemistry in a Campus and Distance Pathway. Am J Pharm Educ. 2008;72(2):Article 31. 15. SoftChalk Cloud. https://SoftChalk ${ }^{\circledR}$ cloud.com/. Accessed February 27, 2020.

16. Alsharif NZ, Henriksen B. Assessment of electronic integration of prerequisite content into a medicinal chemistry course on student learning. Am J Pharm Educ. 2009;73(8):Article 150.

17. Malone PM, Glynn GF, Stohs SJ. The development and structure of a web-based entry level doctor of pharmacy pathway at Creighton University Medical Center. Am J Pharm Educ. 2004;68(2):Article 46. 18. Sakya S, Karki K. Donepezil, Rivastigmine and Galantamine: Cholinesterase Inhibitors for Alzheirmer's Disease. In: Li JJ, Johnson 


\section{American Journal of Pharmaceutical Education 2020; 84 (2) Article 7556.}

DS. Eds. Modern Drug Synthesis. John Wiley \& Sons, Inc. 2010. Pages:249-274. https://onlinelibrary.wiley.com/doi/pdf/10.1002/ 9780470768594.ch17. Accessed February 27, 2020.

19. Peron EP, Slattum PW, Powers KE, Hobgood SE. Alzheimer Disease. In: Pharmacotherapy: A Pathophysiologic Approach. DiPiro JT, Talbert RL, Yee GC, Matzke GR, Wells BG, Posey L. eds. 10e New York, NY: McGraw-Hill.

20. Alzheimer's Association. Health Systems and Clinicians: Alzheimer's Disease Management. https://www.alz.org/ professionals/health-systems-clinicians/management. Accessed February 27, 2020.

21. Sugimoto H, Ogura H, Arai Y, Limura Y, Yamanishi Y. Research and Development of Donepezil Hydrochloride, a New Type of Acetylcholinesterase Inhibitor. Jpn J Pharmacol. 2002; 89(7):7-20.

22. Donepezil. Clinical Pharmacology [Internet]. Tampa (FL): Elsevier. c2016- [cited 2016 April 4]. Available from: http:// www.clinicalpharmacology.com

23. Seltzer B, Zolnouni P, Nunez M, Goldman R, Kumar D, Jeni J, Richardson S. Efficacy of Donepezil in Early-Stage Alzheimer Disease. Arch Neurol. 2004;61(12):1852-1856.

24. Seeley WW, Miller BL. Alzheimer's Disease and other Dementias. In Kasper D, Fauci A, Hauser S, Longo D, Jameson JL, Loscalzo J. Eds. Harrison's Principles of Internal Medicine. 19e, New York, NY: McGraw-Hill.

25. Mustazza C, Borioni A, Rosaria De Giudice M, et al. Synthesis and Cholinesterase activity of phenylcarbamates related to Rivastigmine, a therapeutic agent for Alzheimer's disease. Eur J Med Chem. 2002;37:91-109.

26. Eskander MF, Nagykery NG, Leung EY, Khelghati B, Geula C. Rivastigmine is a Potent Inhibitor of Acetyl- and Butyrylcholinesterase in Alzheimer's Plaques and Tangles. Brain Res. 2005;1060:144-152.

27. Scott LJ, Goa KL. Galantamine: A Review of its Use in Alzheimer's Disease. ADIS Drug Eval. 2000;60(5):1095-1122. 28. Memantine. Clinical Pharmacology [Internet]. Tampa (FL): Elsevier. c2020- [cited 2020]. http://www.clinicalpharmacology.com 29. Schu M, Green RC. Alzheimer Disease. In: Murray MF, Babyatsky MW, Giovanni MA, Alkuraya FS, Stewart DR. eds. Clinical Genomics: Practical Applications in Adult Patient Care, 1e New York, NY: McGraw-Hill; 2014. http://accessmedicine. mhmedical.com/content.aspx? bookid $=1094 \&$ sectionid $=61905763$. Accessed February 27, 2020.

30. Donepezil. Clinical Pharmacology [Internet]. Tampa (FL): Elsevier. c2020- [cited 2020]. http://www.clinicalpharmacology.com. 31. AACP Cumulative Policies 1980-2019. American Association of Colleges of Pharmacy House of Delegates. Policies on Professional Affairs. Page 13. https://www.aacp.org/sites/default/files/2019-11/
Cumulative\%20Policy\%201980-2019\%20FINAL.pdf. Accessed February 27, 2020.

32. Burningham G. Advanced practice pharmacists are ready. UCSF School of Pharmacy. Published November 9, 2017. https:// pharmacy.ucsf.edu/news/2017/11/advanced-practice-pharmacistsare-ready. Accessed February 27, 2020.

33. Snyder ME, Earl TR, Gilchrist S, et al. Collaborative drug therapy management: Case studies of three community-based models of care. Chronic Dis. 2015;12. DOI: http://dx.doi.org/10.5888/ pcd12.140504.

34. Ludmerer KM Time to Heal: American Medical Education from the Turn of the Century to the Era of Managed Care. Oxford, England Oxford University Press 1999.

35. Christakis NA. The similarity and frequency of proposals to reform US medical education: constant concerns. JAMA. 1995;274(9):706-711.

36. Spann SJ. A New Model of Practice: Implications for Medical Student Teaching in Family Medicine. Fam Med. 2005;37(10): 690-692.

37. Ballantine A, Feudtner C. The 10 R's of clinician education. Arch Pediatr Adoles Med. 2010;164(4).

38. Cayley WE. Effective clinical education: Strategies for teaching medical students and residents in the office. WMJ. August 2011;110(4):178-181. http://www.fammed.wisc.edu/files/webfmuploads/documents/med-student/pcc/effictive-clinical-educationcayley.pdf. Accessed February 27, 2020.

39. Alternative Payment Models. American Academy of Paediatrics. https://www.aap.org/en-us/professional-resources/practicetransformation/Implementation-Guide/Pages/Alternative-PaymentModels.aspx. Accessed February 27, 2020.

40. Guidelines for Teaching Physicians, Interns and Residents. Medicare Learning Network. Published March 2018. https:// www.cms.gov/Outreach-and-Education/Medicare-LearningNetwork-MLN/MLNProducts/Downloads/Teaching-PhysiciansFact-Sheet-ICN006437.pdf. Accessed February 27, 2020. 41. Cooley J, Lee J. Implementing the Pharmacists' Patient Care Process at a Public Pharmacy School. Am J Pharm Educ. 2018;82(2):Article 6301.

42. Rivkin A. Thinking Clinically from the Beginning: Early Implementation of the Pharmacists' Patient Care Process. Am J Pharm Educ. 2016;80(10):Article 164.

43. Bourg Rebitch C, Fleming VH, Palmer R, Rong H, Choi I. Evaluation of Video-Enhanced Case-Based Activities Guided by the Pharmacists' Patient Care Process. Am J Pharm Educ. 2019; 83(4), 6676. 44. Gonyeau MJ, DiVall M, Conley MP, Lancaster J. Integration of the Pharmacists' Patient Care Process into a Comprehensive Disease Management Course Series. Am J Pharm Educ. Am J Pharm Educ. 2019;83(3), 7400, 


\section{American Journal of Pharmaceutical Education 2020; 84 (2) Article 7556.}

Appendix 1. Summary of the Key Information for Sections I-VI of the SoftChalk Lesson for the Cholinesterase Inhibitors and N-methyl-D-aspartate (NMDA) Receptor Antagonist ${ }^{18-30}$

\section{Lesson Section}

I. Introduction

II. Pharmacophore

III. Structure Activity Relationship

IV. Apply SAR to Marketed Products

V. Summary of Most Common Clinical Decisions

VI. Predict Clinical Activity
Key Information

The mechanism of action of CIs and NMDA Receptor antagonist, their clinical use, and the etiology and signs and symptoms of each stage of AD were introduced, as were key aspects of the pharmacology of each marketed drug along with the rationale for the use of these drugs.

The pharmacophores for all marketed CIs and the NMDA antagonist were introduced (Figure 1) with a specific reference to which pharmacophore is used for mild-moderate or severe AD. The NMDA receptor antagonist pharmacophore was introduced as the first therapy approved for the more advanced stages of $\mathrm{AD}$ when both the functional and behavioral symptoms, and caregiver burden become significant. ${ }^{18-20}$ For initial therapy, it was emphasized that there is no evidence that one pharmacophore (drug) that is approved for use in mild-moderate disease is better than another, or with regard to patient outcomes since there are no head-to-head clinical trials among the marketed pharmacophores (drugs). ${ }^{18-20}$

In addition to introducing all the key SARs for the three marketed CIs and the NMDA receptor antagonist, aspects of the SAR which may affect any of the seven criteria for therapeutic decision making, thus the first three steps of the PPCP, were emphasized. For example, for the benzylpiperidine derivative (donepezil, Aricept), based on the presence of specific functional features, metabolism is discussed and students are expected to predict possible metabolism by CYP2D6 and CYP3A4 via demethylation, debenzylation, hydroxylation, oxidation to the cisN-oxide, and glucuronidation. ${ }^{21,22}$ Thus, students should collect information regarding other drugs the patient is taking, and in particular drugs which are CYP450 inhibitors such as ketoconazole, assess the significance of any potential drug-drug interaction and plan the drug therapy accordingly. Also, the benzylpiperidine derivative produces a 6-O-desmethyl metabolite which accounts for $11 \%$ of a dose and exhibits acetylcholinesterase inhibitory activity comparable to that of the parent compound. Students should recognize that this will increase the elimination half-life and explain the once a day dosing for this drug. ${ }^{21,22}$ In addition, the benzylpiperidine based on its SAR has a higher affinity for the central nervous system (CNS) cholinesterase enzyme, and as such is expected to have decreased potential for peripheral side effects. ${ }^{18,19,22-24}$ Thus, with the ease of administration with the once a day dosing and the decrease in peripheral side effects, the benzylpiperidine derivative is a good choice to enhance patient adherence.

For the arylcarbamate, benzazepine derivative (Galantamine, Razadyne) and the 3,5dimethyladamantan-1-amine derivative (Memantine, Namenda), ${ }^{18-30}$ please refer to the lesson link for the details. https://SoftChalkcloud.com/lesson/serve/fRoEcJtPQgN50B/html

The students were challenged to apply the SAR and relevant clinical information to each of the marketed products and relate the information to our patient S.A. or variations in the presentation of S.A. (eg, if the symptoms were mild, which structure would be used? Or, if S.A. has a true allergy to carbamate, which structure would be contraindicated?).

Students are challenged to summarize all the common clinical decisions which can be ascertained from and predicted by the structure as discussed in sections (I-IV). Students are also reminded that the PPCP is a systematic process for pharmacists to approach patient care.

Students are provided with all the marketed products and asked to conduct a SBTE based on specific clinical scenarios (https://SoftChalkcloud.com/lesson/serve/fRoEcJtPQgN50B/html) related to our patient S.A. The goal is to challenge them as they analyze drug structure to recall the type of information which they need to collect and assess before planning a therapy, deciding on a drug structure based on a patient scenario, and ultimately to plan, implement and follow-up on the therapy. 


\section{American Journal of Pharmaceutical Education 2020; 84 (2) Article 7556.}

Appendix 2. Alzheimer's Disease Case Study for the Cholinesterase Inhibitors and N-methyl D-aspartate Receptor Antagonist Lesson.

S.A. is a 59 y/o Caucasian female who was diagnosed with AD based on significant impairment in memory, communication and language. Over the first year, she demonstrated progressive decline in memory, thinking and reasoning skills which required the hiring of a caregiver. S.A. was started on drug therapy and showed some improvement. However, gradually the effects of drug therapy faded. S.A.'s symptoms worsened over time and she was not able to recognize her family. Over the course of 7 years, she started wandering and experienced incontinence, demonstrated aggressive behavior and became more dependent on the caregiver/ children for ADL. 